\title{
IN VITRO AND IN VIVO EFFICIENCY OF FENNEL ESSENTIAL OIL AGAINST TOMATO FUSARIUM WILT AND ITS PROMOTION EFFECT ON PLANT GROWTH
}

\author{
Fatma Kalleli $^{1,2}$, Ibtissem Ben Salem ${ }^{3}$, Nä̈ma Boughalleb-M'Hamdi ${ }^{3}$ and Mahmoud M'Hamdi',2 \\ ${ }^{1}$ Horticultural Science Laboratory, National Agronomic Institute of Tunisia. University of Carthage, Tunisia, \\ ${ }^{2}$ Université de Sousse, Institut Supérieur Agronomique de Chott Meriem, 4042, Sousse, Tunisie, \\ ${ }^{3}$ Université de Sousse, Institut Supérieur Agronomique de Chott Meriem, Département des sciences biologiques et \\ de la protection des végétaux, UR13AGR0, 4042, Sousse, Tunisie,
}

http://doi.org/10.35410/IJAEB.2019.4417

\begin{abstract}
In the present study, the potential biocontrol ability of fennel seeds essential oil against Fusarium oxysporum f. sp. lycopersici (FOL), in vitro and in vivo conditions was evaluated. Chemical composition of the essential oil was determined by GC-MS analysis and major components identified were trans-anethole, L-Fenchone, Estragole and Limonene. The different essential oils concentrations revealed to be efficient to inhibit the FOL growth with IC50 values $=300.37 \mu 1 / 1$. Under greenhouse conditions using susceptible tomato plants, the use fennel essential oil as a curative treatment, resulted in a good protection against Fusarium wilt. In fact, the essential oil displayed a significant decrease $(42.85 \%)$ in disease severity on tomato in comparison to control. Treatment with fennel essential oil significantly exhibited a growth promotion of infected or non-infected tomato plants. Moreover, the resistance induction was associated with several physiological changes in tomato plants. After 3 weeks post infection, physiological parameters such as, relative water content, total chlorophyll and carotenoid contents were altered by FOL and interestingly increased in fennel essential oil treated plants. This study demonstrated that fennel seeds essential oil was a promising biocontrol compound and could be considered in formulation of biofungicide used against Fusarium wilt.
\end{abstract}

Keywords: Antifungal activity, Essential oil, Fennel, Fusarium wilt.

\section{INTRODUCTION}

Tomato (Lycopersicon esculentum Mill) fruits is an important source of Vitamins A, B and C which gives them high nutritional value and antibiotic properties [1]. However, this culture could be infected, at all the stages of development, by many soil-borne pathogens leading to the decrease of tomato production [2], such a, Fusarium oxysporum f. sp. lycopersici (FOL) responsible of Fusarium wilt) which is a severe and destructive disease of Tomato [1]. Used approaches for controlling Fusarium wilt have largely been so fare ineffective because of soilborne nature and emergence of new races of the pathogen that are able to overcome resistance genes in currently grown cultivars [3]. Despite their efficiency, synthetic fungicides cause some serious ecological, environmental and health concerns [4]. These among other factors have led to 
the quest for alternatives. Various types of medicinal plant extracts are gaining interest for resistance induction due to their potential effectiveness as biopesticides [5]. The potential exploitation of essential oils and their constituents as eco-friendly fungi-toxicants is reinforced by their biodegradability [6]. In addition, the appearance of fungal strains resistant to fungicides based on essential oils is highly improbable because of the polymolecular composition of these oils and the synergistic action of their constituents [7]. The medicinal plant products have potential to fungi control due to the presence of elicitor compounds or by direct fungitoxic effects [8]. Among the aromatic seed spices, fennel (Foeniculum vulgare Mill), belonging to the Umbelliferae family, is a perennial or annual herbaceous that grows in several regions all over the world [9]. It is generally used as herbal remedy for a variety of therapeutic purposes as an antiseptic, analgesic, antioxidant, antispasmodic, anti-inflammatory, carminative, digestive, and diuretic [10]. The presence of Trans-Anethole and fenchone, the major components of fennel essential oil, have been reported possessing inhibitory activity against several microbial strains [11]. Therefore, the aim of the current study is to evaluate in vivo, the efficacy of fennel essential oil for controlling Fusarium wilt disease in tomato plants by considering some agronomic and physiological parameters.

\section{MATERIALS AND METHODS}

\subsection{Plant material and essential oil isolation}

Fennel seeds used in this study belong to the harvest of a seed multiplication assay conducted in the experimental farm of the Higher Agronomic Institute of Chott Mariem (Sousse, Tunisia). Essential oil of fennel seeds was extracted according to the method of Bettaieb Rebey et al. [12]. Whole air-dried seeds (50g) were subjected to hydrodistillation for 180 min using a Clevengertype apparatus.

\subsection{Gas Chromatography-Mass Spectrometry (GC-MS) analysis}

Essential oil analysis was performed on an Agilent GC system 7890A coupled with a mass spectrometer Agilent 5975C inert XL MSD with electron impact ionization (70 eV). An HP-5MS capillary column $(30 \mathrm{~m} \times 0,25 \mathrm{~mm}$ coated with $5 \%$ phenyl methyl silicone, $95 \%$ dimethylpolysiloxane, $0,25 \mu \mathrm{m}$ film thickness) was used. Oven temperature was programmed at $40{ }^{\circ} \mathrm{C}$ for $1 \mathrm{~min}$, then heated to $100^{\circ} \mathrm{C}$ at a rate of $8{ }^{\circ} \mathrm{C} / \mathrm{min}$, and then kept constant at $100^{\circ} \mathrm{C}$ for $5 \mathrm{~min}$, then heated to $200{ }^{\circ} \mathrm{C}$ at a rate of $10{ }^{\circ} \mathrm{C} / \mathrm{min}$, and then kept constant at $200^{\circ} \mathrm{C}$ for $3 \mathrm{~min}$, finally it rised to $300^{\circ} \mathrm{C}$ at a rate of $12{ }^{\circ} \mathrm{C} / \mathrm{min}$, transfer line temperature was $250{ }^{\circ} \mathrm{C}$. The carrier gas was He with a flow of $0.9 \mathrm{ml} / \mathrm{min}$ and a split ratio of 50/1. Scan time and mass range were $1 \mathrm{~s}$ and $50-550 \mathrm{~m} / \mathrm{z}$, respectively. The identification of volatile components was assigned by matching their recorded mass spectra with those stored in the Wiley 09 NIST 2011 mass spectral library of the GC/MS data system.

\subsection{Anti-Fusarium oxysporum lycopersici of fennel essential oil in vitro conditions}

\subsubsection{Fungal strains}


The pure culture of the pathogen belongs to the fungal collection of the Phytopathology Laboratory of the Higher Agronomic Institute of Chott-Mariem.

\subsubsection{In vitro antifungal effects of fennel essential oil}

\section{a. Mycelia growth}

Different concentrations of essential oil were prepared by dissolving the required amounts in a sterile solution of Tween $20(0.1 \%, \mathrm{v} / \mathrm{v})$ to obtain different concentrations of 15.62, 31.25, $62.50,125,250$ and $500 \mu 1 . m l-1$. Resulting amounts of these solutions were added to individual Petri dishes containing $20 \mathrm{ml}$ of PDA medium. After the medium solidification, agar discs (7 mm diameter) from the edge of actively growing cultures of FOL were placed in the center of each Petri dish containing the essential oil and the PDA medium [13]. Petri dishes composed of PDA medium, Tween 20 and FOL served as a controls. The treated media were incubated at $28^{\circ} \mathrm{C}$ until the control invaded completely the plate. Mycelial growth has been assessed daily by measuring the horizontal and vertical diameters of the colony. For each concentration, three replicate plates were used. The Mean mycelial growth values of the pathogen were determined by measuring the horizontal and vertical diameters of the colony. The IC50 values were calculated by probit analysis.

\section{b. Effects of essential oil on morphological characteristics of FOL}

Morphological alterations caused by fennel essential oil were evaluated in a sample of mycelium taken from the periphery of a 3-days-old fungal colony grown at $28^{\circ} \mathrm{C}$ containing the essential oil (500 $\mu 1 . \mathrm{ml}-1)$. The samples were fixed with lacto-phenol-cotton blue stain and observed under the microscope at ( $\mathrm{Gr} \mathrm{X} 40$ ) to examine morphological abnormalities. Control assay without essential oil was tested in the same way [14].

\subsection{In planta antifungal effects of fennel essential oil}

\subsubsection{Preparation of pathogen inoculums}

The assay was carried out under greenhouse controlled experiment using tomato cv. Murano. Spore suspensions were prepared from pure cultures of FOL on PDA medium incubated for 1 week. The mycelium was subsequently diluted in $50 \mathrm{ml}$ of PDB medium (Potato Dextrose Broth), and thus incubated for 5 to 8 days with continuous stirring to promote the multiplication of spores. Then, the concentration was determined by observation under a microscope using a malassez cell and adjusted by dilutions at the concentration of 106 spores / $\mathrm{ml}$.

\subsubsection{Essential oil application and pathogen Inoculation}

The trial was conducted in completely randomized block design with 3 replicates (blocks). The trans $\neg$ planted tomato plants were grown until the development of seven leaves; then, they were inoculated with $1 \mathrm{~mL}$ of spore suspension each. Controls were irrigated with sterile distilled water. The artificial inoculation was applied the same day for all treatments. The fennel essential oil application was performed with the concentration showing the most significant in vitro inhibition rate $(500 \mu \mathrm{L} / \mathrm{mL})$. The evaluation of the antifungal potential of the essential oil in vivo 
was determined by irrigation (approximately $1 \mathrm{~mL}$ per plant), one week before inoculation for preventive treatment, and two weeks after inoculation for curative treatment. There were six treatments which were as follows: T1: Control (-) (sterile distilled water), T2: Control (+) (Tachigaren), T3: treated only with essential oil, T4: Plants inoculated only with FOL, T5: Plants inoculated and treated with fungicide, T6: Plants treated with essential oil before inoculation and T7: Plants inoculated and treated with essential oil after inoculation.

\subsubsection{Disease severity assessment}

Evaluation parameter considered for testing the inhibitory effect of the tested antifungal agents against the pathogen was the disease severity according to a scale varying from 0 to 4 as described by Song et al. [15] where:

0 : No infection,

1: Slight infection which is about $25 \%$ of full scale. One or two leaves became yellow.

2: Moderate infection. Two or three leaves became yellow, $50 \%$ of leaves became wilting.

3: Extensive infection. The all plant leaves became yellow, $75 \%$ of leaves became wilting, and growth was inhibited.

4: Complete infection. The whole plant leaves became yellow, 100\% of leaves became wilting, and the plant was died.

The incidence rate of the disease was assessed using the following formula:

Disease incidence $(\%)=\left(\right.$ scale number of plants infected) $\frac{100}{\text { (highest acalestotal number of plants) }}$

\section{Growth Parameters}

Vegetative growth of tomato plants was assessed by measuring o the plant length (L), number of leaves (NL), number of flowers (NF), stem diameter (SD) and plant biomass (RB and LB). Traits assessment was performed on ten plants for each treatment and block. Foliar and root dry biomass were obtained after drying plants in an oven at $70^{\circ} \mathrm{C}$ for 3 days until a stable weight value was obtained.

The dry matter content (\% DM) of the aerial and roots parts was calculated as follows:

$\% D M=\frac{D W}{F W} * 100$

DM: Dry matter, DW: dry weight (g), FW: fresh weight (g).

Physiological parameters

Estimation of Chlorophyll Content 
Disease development was also determined by observing the chlorophyll content $(\mathrm{Chl} \mathrm{a}, \mathrm{Chl} \mathrm{b}$, and total chlorophyll). For this, $0.1 \mathrm{~g}$ of tomato leaves was extracted with $80 \%$ acetone.

Chlorophyll contents were estimated by measuring the absorbance at 645 and $663 \mathrm{~nm}$. Then chlorophyll a, b, and total chlorophyll were calculated according to Lichtenhaler and Wellbum [16]:

$$
\begin{aligned}
& \text { Chl a }(\mathrm{mg.g}-1 \text { leaf fresh weight })=\left(12.7(\text { OD 663) }-2.69(\text { OD } 645)) * \frac{\mathrm{V}}{1000} * \mathrm{~W}\right. \\
& \text { Chl b }(m g . g-1 \text { leaf fresh weight })=\left(22.9(\text { OD } 645) \_4.68(\text { OD } 663)\right) * \frac{v}{1000} * w \\
& \text { Total Chl }(m g . g-1 \text { leaf fresh weight })=(20.2(\text { OD } 645)+8.02(\text { OD } 663)) * \frac{v}{1000} * w
\end{aligned}
$$

Where;

OD = Optical Density,

$\mathrm{V}=$ Volume of sample,

$\mathrm{W}=$ Weight of sample.

Estimation of carotenoids content

The extract used for chlorophyll estimation was also used for total carotenoids determination. Absorbance of the extract was noted at 480, 645 and $663 \mathrm{~nm}$ and total carotenoids content was calculated using the following formula:

Total carotenoids $(\mathrm{mg} \cdot g-1$ leaf fresh weight $)=($ OD $480+0.114($ OD 663$)-0.638($ OD 645$))$

(6)

Estimation of relative water content

The relative water content (RWC) was calculated from the following equations:

$$
R W C=\left(\frac{F W-D W}{T W-D W}\right) * 100
$$

Where;

$\mathrm{FW}=$ fresh weight of leaves

$\mathrm{DW}=$ dry weight of leaves,

TW $=$ fresh weight of leaves after 24-h incubation in distilled water when their cells achieved maximum turgor [17]. 


\section{Statistical analysis}

Data were analyzed using ANOVA and subsequent comparison of means was performed using the Duncan's Test at 5\% probability. Multiple linear regression analysis (stepwise) and Principal component analysis (PCA) were used to analyse the relationship between the variables studied by using XLSTAT-2017.

\subsection{RESULTS}

\section{Essential oil composition}

The essential oil was subjected to detailed GC-MS analysis and total ion chromatogram of the tested oil was shown in Figure 1. The essential oil is trans-anethole rich. Indeed, trans-anethole, a phenylpropanoid derivative was the main compound with proportion of $78.26 \%$. Fenchone $(10.64 \%)$, estragole $(4.67 \%)$ and limonene $(3.88 \%)$ were the others major components identified in the fennel essential oil.

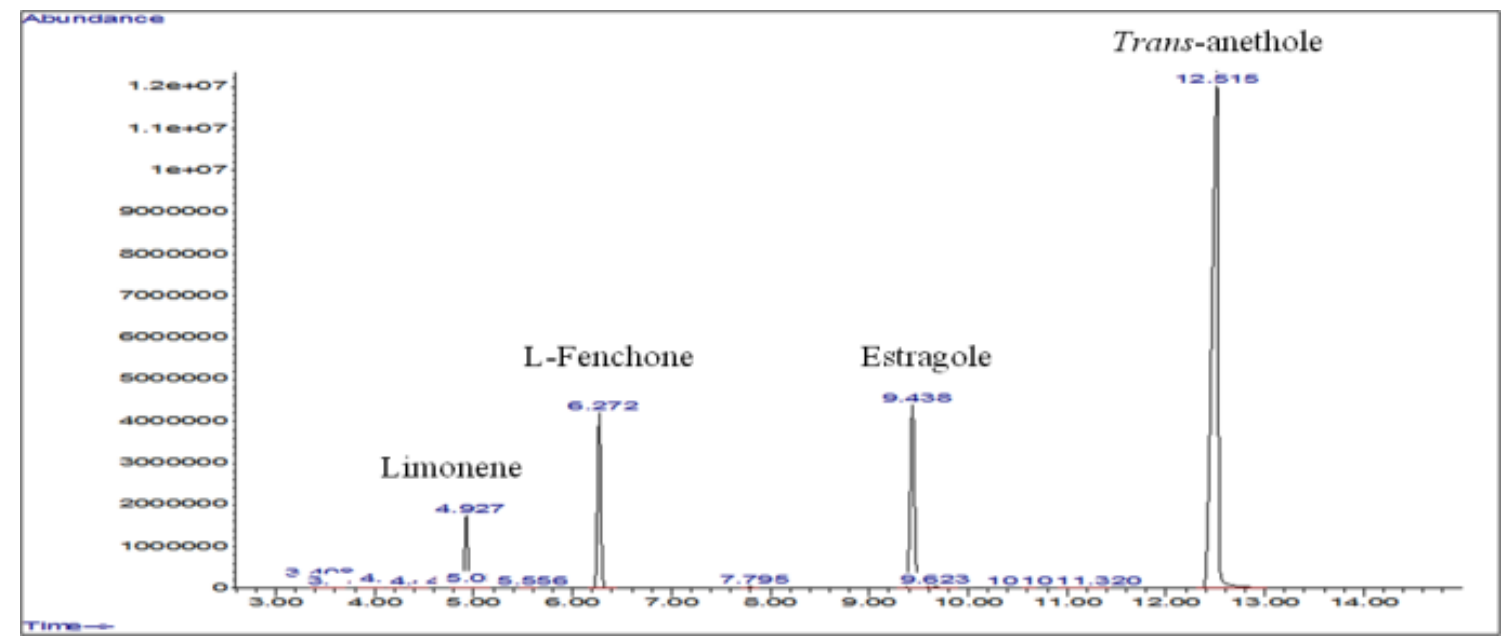

Figure 1: Total ion chromatograms of the fennel seed essential oils.

3.2.Anti-Fusarium oxysporum lycopersici of fennel essential oil in vitro conditions

\subsubsection{Effects of essential oil on mycelia growth}

The result of antifongic effect of fennel essential oil indicated that mycelia growth of FOL was decreased at the concentration of $500 \mu \mathrm{L} / \mathrm{mL}$. Inhibition of mycelial growth started after the second day at $500 \mu \mathrm{L} / \mathrm{mL}$ and $250 \mu \mathrm{L} / \mathrm{mL}$, and after three days for the other concentrations. After 6 days of incubation at $28^{\circ} \mathrm{C}$, all tested concentrations of fennel essential oil exhibited inhibitory effect against FOL and the efficient concentration (IC50) value was $300.37 \mu \mathrm{L} / \mathrm{mL}$. Increasing levels of essential oil doses allowed greater inhibition of the mycelial growth (Figure 2). 

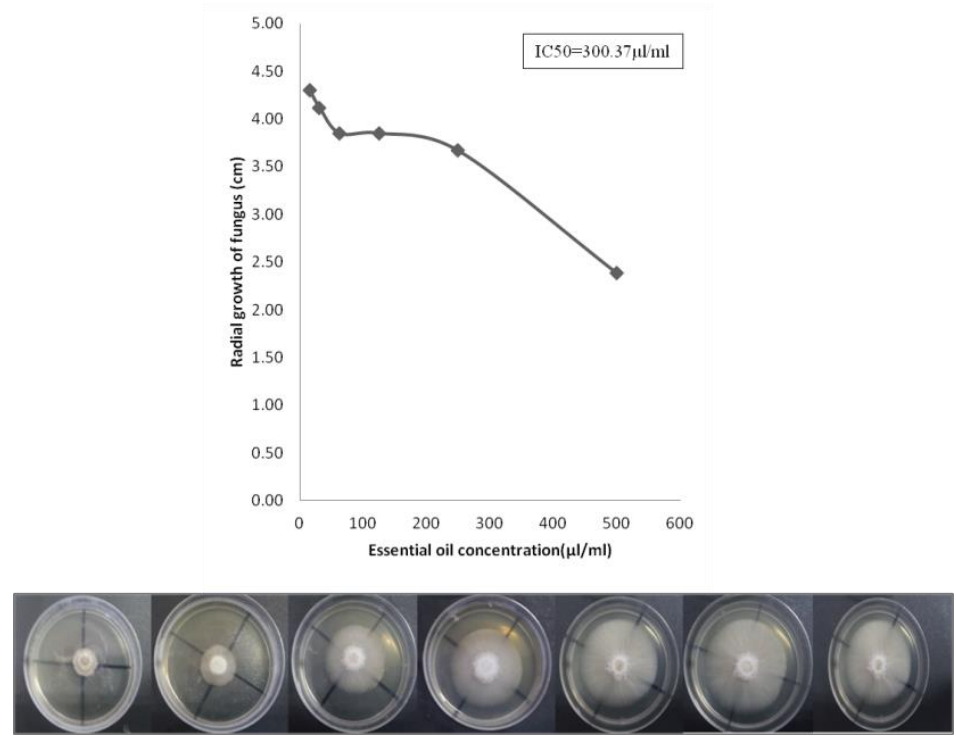

Figure 2: Effect of fennel essential oil on mycelial growth $(\mathrm{cm})$ of Fusarium oxysporum f. sp. lycopersici by using the direct method.

\subsubsection{Effects of essential oil on morphological characteristics of FOL}

The observations of FOL examined under the light microscope at $40 \mathrm{x}$ magnification, after exposure to $500 \mu \mathrm{l} . \mathrm{ml}-1$ of fennel essential oil are presented in Figure 3. Microscopic examination of the control mycelium of FOL revealed regular cell structure, clearly visible conidia and phialide (Figure 3a). However, treatment with essential oil exhibited morphological alterations in cellular structures and cell surface compared with the control (Figure 3b, c and d).The found morphological changes were the development of mycelia cordons (Figure 3b), lysis of fungal mycelia (Figure 3c) and mycelia cell vacuolization with distorted presence of chlamydospores (Figure 3d).

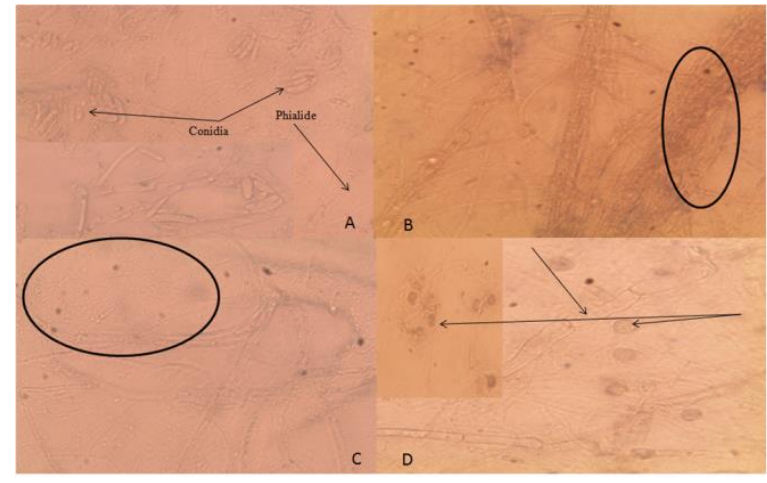

Figure 3: Light microphotographs of FOL mycelium growing without or with fennel seeds (500 $\mu \mathrm{L} / \mathrm{mL}$ ) essential oil during 3 days of incubation at $28^{\circ} \mathrm{C}$. a: control: short phialid with presence of micro and macroconidia; for the other b: mycelial cords; $c$ : lysis of fungal mycelia and $\mathrm{d}$ : chlamydospore formation and mycelial cell vacuolization (Gr X 40) 


\subsection{In vivo antifungal activity of fennel essential oil on tomato plants}

\subsubsection{Growth parameters}

Treatments effects were highly significant for all the studied growth traits, except root biomass (Tables 1,2$)$. Plants inoculated by only the pathogen $(p<0.05)$ showed a significant decrease of plant length, number of leaves, diameter of stem, number of flowers, foliar dry matter, foliar fresh weight, foliar dry weight and root fresh weight. This reduction was stimulated by the increasing of the infection period. Fruits number and weight were also affected by the infection (Table 3); the fruit weight was reduced from $47.65 \mathrm{~g}$ for healthy plants to $5.64 \mathrm{~g}$ for inoculated plants. Such increase in growth traits may be the consequence of essential oil and standard fungicide applications. Indeed, treatments with antifungal agents enhanced plant growth of inoculated plants, the extent of such increases was much more pronounced when essential oil was applied 14 days after inoculation (T7). Comparison between inoculated and treated plants showed that the most developed plant $(105.55 \mathrm{~cm}$ at 56 days after inoculation) was observed plants treated by essential oil and the shortest plant was recorded in Fusarium infected plants without treatment (T4). Treated plants by essential oils showed also the highest number of leaves/plant (13, 11.55,9.77 at 28, 42 and 56 days after inoculation, respectively ), stem diameter $(5.77,6.52,7.34 \mathrm{~mm}$ at 28, 42 and 56 days after inoculation, respectively), number of flowers $(8,7.44,7.88$ at 28,42 and 56 days after inoculation, respectively), leaves biomass (15.12\%, $13.87 \%, 12.55 \%$ at 28,42 and 56 days after inoculation, respectively) and roots biomass $(8.89 \%$, $8.23 \%, 8.57 \%$ at 28, 42 and 56 days after inoculation, respectively). Moreover, the performance of these treatments was evaluated in plants not inoculated by the pathogen. Interestingly, healthy plants treated with fennel essential oil (T3) showed significant increases in their growth parameters as compared with untreated healthy plants (T1).

Table1. Treatment and infection period effects on the plant height $(H)$, number of leaves (NL), stem diameter (SD) and number of flowers (NF) of tomato plants grown under different treatment measured at 28, 42 and 56 days after inoculation.

\begin{tabular}{|c|c|c|c|c|c|c|c|c|}
\hline Parameters & Infection period & T1 & T2 & T3 & T4 & T5 & T6 & $T 7$ \\
\hline \multirow{3}{*}{$\mathrm{H}(\mathrm{cm})$} & P1 & $85.00 \pm 10.488^{a^{*}}$ & $85.33 \pm 8.529^{\mathrm{a}}$ & $87.11 \pm 6.9^{\mathrm{a}}$ & $79.78 \pm 11.893$ a & $81.00 \pm 7.730^{\mathrm{a}}$ & $81.78 \pm 7.997^{a}$ & $84.78 \pm 2.048^{a}$ \\
\hline & P2 & $104.67 \pm 4.924$ ab & $99.67 \pm 5.362$ abc & $106.33 \pm 12.288^{a}$ & $93.11 \pm 3.551^{\mathrm{c}}$ & $98.67 \pm 7.500^{b c}$ & $95.56 \pm 7.468^{\mathrm{C}}$ & $99.00 \pm 4.555$ bc \\
\hline & P3 & $111.67 \pm 4.243$ ab & $107.44 \pm 3.358^{\mathrm{bc}}$ & $116.89 \pm 12.221^{\mathrm{a}}$ & $95.44 \pm 3.087^{d}$ & $103.78 \pm 7.120^{\circ}$ & $102.67 \pm 6.946^{\mathrm{c}}$ & $105.56 \pm 5.388^{\mathrm{bc}}$ \\
\hline \multirow{3}{*}{ NL } & P1 & $9.89 \pm 1.62^{a}$ & $9.89 \pm 2.09 \mathrm{a}$ & $10.00 \pm 1.66^{a}$ & $9.22 \pm 1.39 \mathrm{a}$ & $9.78 \pm 1.79$ a & $9.44 \pm 1.24$ a & $9.78 \pm 1.64$ a \\
\hline & P2 & $12.78 \pm 0.83^{\mathrm{a}}$ & $12.56 \pm 2.65 \mathrm{a}$ & $13.00 \pm 1.87^{a}$ & $10.67 \pm 1.22^{b}$ & $11.56 \pm 1.74$ ab & $11.11 \pm 1.27^{\mathrm{b}}$ & $11.56 \pm 1.50$ ab \\
\hline & P3 & $13.44 \pm 0.53$ ab & $13.78 \pm 2.17$ ab & $13.89 \pm 1.69^{\mathrm{a}}$ & $11.33 \pm 1.00^{d}$ & $12.56 \pm 1.74 \mathrm{bc}$ & $12.11 \pm 1.27^{\mathrm{cd}}$ & $13.00 \pm 1.22 \mathrm{abc}$ \\
\hline \multirow{3}{*}{$\mathrm{SD}(\mathrm{mm})$} & P1 & $5.93 \pm 0.26^{\mathrm{a}}$ & $5.83 \pm 0.35$ a & $6.08 \pm 0.37^{\mathrm{a}}$ & $4.74 \pm 0.85^{b}$ & $5.04 \pm 0.90^{b}$ & $4.99 \pm 1.89^{b}$ & $5.78 \pm 0.80^{\mathrm{a}}$ \\
\hline & P2 & $6.99 \pm 0.93^{\mathrm{a}}$ & $6.82 \pm 1.18^{a}$ & $7.04 \pm 0.45^{a}$ & $5.67 \pm 1.10^{b}$ & $6.39 \pm 1.04$ ab & $6.48 \pm 1.15 \mathrm{ab}$ & $6.53 \pm 1.96^{a}$ \\
\hline & P3 & $7.81 \pm 0.98^{\mathrm{a}}$ & $7.56 \pm 1.08$ ab & $7.91 \pm 0.42^{\mathrm{a}}$ & $6.64 \pm 1.83^{c}$ & $6.69 \pm 1.06^{b c}$ & $7.18 \pm 0.99 \mathrm{abc}$ & $7.34 \pm 1.13 \mathrm{abc}$ \\
\hline
\end{tabular}




\section{International Journal of Agriculture, Environment and Bioresearch}

Vol. 4, No. 04; 2019

ISSN: $2456-8643$

\begin{tabular}{|c|c|c|c|c|c|c|c|c|}
\hline & P1 & $8.11 \pm 3.10^{a b}$ & $8.33 \pm 3.43 \mathrm{ab}$ & $9.78 \pm 1.64$ a & $6.22 \pm 4.21^{b}$ & $7.11 \pm 2.57$ ab & $7.56 \pm 3.47 \mathrm{ab}$ & $8.00 \pm 3.35 \mathrm{ab}$ \\
\hline \multirow[t]{2}{*}{$\mathrm{NF}$} & P2 & $8.33 \pm 4.82^{a}$ & $8.33 \pm 1.66^{a}$ & $8.44 \pm 3.32^{a}$ & $5.89 \pm 2.37^{a}$ & $7.33 \pm 2.24$ a & $7.11 \pm 2.67^{a}$ & $7.44 \pm 3.00^{a}$ \\
\hline & P3 & $8.56 \pm 1.33^{a}$ & $7.56 \pm 1.24^{a b}$ & $9.00 \pm 2.12^{a}$ & $4.56 \pm 1.24^{c}$ & $6.67 \pm 1.73^{b}$ & $7.22 \pm 1.72^{a b}$ & $7.89 \pm 2.57^{\mathrm{ab}}$ \\
\hline
\end{tabular}

* Means \pm standard error within a column followed by the same letter are not significantly different according to Duncan's test at $\mathrm{P}<0.05$.

* T1: Control (-), T2: Control (+) (Tachigaren), T3: treated only with essential oil, T4: Plants inoculated only with FOL, T5: Plants inoculated and treated with fungicide, T6: Plants treated with essential oil before inoculation and T7: Plants inoculated and treated with essential oil after inoculation.

Table 2: Treatment and infection period effects on aerial fresh weight (AFW), aerial dry weight (ADW), aerial biomass (AB), root fresh weight (RFW), root dry weight (RDW) and root biomass $(\mathrm{RB})$ of the tomato plants grown under different treatment 28,42 and 56 days after inoculation.

\begin{tabular}{|c|c|c|c|c|c|c|c|c|}
\hline Prameters & Infection period & $\mathrm{T} 1$ & T2 & T3 & T4 & T5 & T6 & 77 \\
\hline \multirow[b]{3}{*}{ AB } & P1 & $20.18 \pm 3.33^{\mathrm{a}}$ & $15.73 \pm 3.51 \mathrm{ab}$ & $17.73 \pm 1.94$ ab & $12.62 \pm 5.58^{b}$ & $15.73 \pm 1.32^{\mathrm{ab}}$ & $13.95 \pm 3.50$ ab & $15.12 \pm 1.36$ ab \\
\hline & P2 & $21.23 \pm 10.33$ ab & $21.37 \pm 2.47 \mathrm{ab}$ & $27.84 \pm 12.55^{\mathrm{a}}$ & $10.35 \pm 3.34^{b}$ & $12.36 \pm 3.54^{b}$ & $13.21 \pm 0.5^{b}$ & $13.87 \pm 1.03^{b}$ \\
\hline & P3 & $22.95 \pm 8.80^{\mathrm{ab}}$ & $22.98 \pm 6.15^{\mathrm{ab}}$ & $27.95 \pm 12.16^{\mathrm{a}}$ & $9.95 \pm 4.94^{c}$ & $12.05 \pm 0.57^{\mathrm{bc}}$ & $11.12 \pm 1.66 \mathrm{bc}$ & $12.59 \pm 3.99 \mathrm{bc}$ \\
\hline \multirow[b]{3}{*}{ AFW } & P1 & $130.33 \pm 21.01$ abc & $144.97 \pm 20.72 \mathrm{ab}$ & $152.93 \pm 10.31^{\mathrm{a}}$ & $108.47 \pm 20.93^{c}$ & $116.67 \pm 21.88 \mathrm{bc}$ & $123.83 \pm 1.44$ abc & $124.07 \pm 4.95$ abc \\
\hline & $\begin{array}{l}\text { P2 } \\
\end{array}$ & $93.73 \pm 41.36^{\mathrm{a}}$ & $84.87 \pm 35.37 \mathrm{ab}$ & $94.57 \pm 49.84 \mathrm{a}$ & $26.23 \pm 6.91^{c}$ & $35.90 \pm 17.11 \mathrm{bcc}$ & $29.27 \pm 0.47^{c}$ & $30.47 \pm 1.00^{c}$ \\
\hline & P3 & $99.97 \pm 38.40^{\mathrm{a}}$ & $96.20 \pm 33.52^{\mathrm{a}}$ & $100.20 \pm 51.09^{a}$ & $11.23 \pm 0.55^{b}$ & $14.93 \pm 1.33^{b}$ & $23.07 \pm 1.09^{b}$ & $23.40 \pm 3.06^{b}$ \\
\hline \multirow{4}{*}{ ADW } & P1 & $25.87 \pm 1.61^{\mathrm{a}}$ & $22.33 \pm 1.84 \mathrm{ab}$ & $27.00 \pm 1.48^{\mathrm{a}}$ & $13.90 \pm 7.14^{c}$ & $18.17 \pm 1.89 \mathrm{bc}$ & $17.30 \pm 4.45 \mathrm{bc}$ & $18.77 \pm 1.92 \mathrm{bc}$ \\
\hline & P2 & $17.10 \pm 0.62^{\mathrm{a}}$ & $17.77 \pm 6.19^{\mathrm{a}}$ & $22.17 \pm 5.69^{a}$ & $2.57 \pm 0.31^{b}$ & $4.03 \pm 0.51^{b}$ & $3.53 \pm 0.38 b$ & $4.23 \pm 0.45 \mathrm{~b}$ \\
\hline & & & & & & & & \\
\hline & P3 & $20.70 \pm 1.31^{\mathrm{a}}$ & $21.07 \pm 4.33^{\mathrm{a}}$ & $23.87 \pm 5.48^{\mathrm{a}}$ & $1.10 \pm 0.50^{b}$ & $1.80 \pm 0.20^{\mathrm{b}}$ & $2.57 \pm 0.42^{b}$ & $2.87 \pm 0.68^{b}$ \\
\hline \multirow[b]{3}{*}{ RB } & P1 & $9.15 \pm 3.10^{\mathrm{a}}$ & $8.69 \pm 2.23$ a & $8.61 \pm 1.43^{a}$ & $6.56 \pm 0.79^{a}$ & $8.69 \pm 2.87^{a}$ & $8.45 \pm 1.83^{a}$ & $8.89 \pm 2.36^{a}$ \\
\hline & P2 & $8.52 \pm 4.24^{a}$ & $6.08 \pm 0.82$ a & $7.50 \pm 2.31^{\mathrm{a}}$ & $3.89 \pm 4.39 \mathrm{a}$ & $6.26 \pm 1.94 \mathrm{a}$ & $8.54 \pm 1.03$ a & $8.24 \pm 3.11^{\mathrm{a}}$ \\
\hline & P3 & $4.91 \pm 3.60^{\mathrm{a}}$ & $4.99 \pm 1.20^{\mathrm{a}}$ & $7.17 \pm 2.19^{a}$ & $8.07 \pm 5.65^{a}$ & $6.27 \pm 4.39^{\mathrm{a}}$ & $7.05 \pm 1.60^{a}$ & $8.58 \pm 3.68^{a}$ \\
\hline \multirow[b]{3}{*}{ RFW } & P1 & $20.47 \pm 5.01^{\mathrm{ab}}$ & $21.27 \pm 2.40^{\mathrm{a}}$ & $22.77 \pm 2.91^{\mathrm{a}}$ & $12.53 \pm 2.35^{c}$ & $13.63 \pm 2.78^{c}$ & $15.47 \pm 1.31 \mathrm{bc}$ & $17.53 \pm 1.00 \mathrm{abc}$ \\
\hline & P2 & $18.07 \pm 4.77^{\mathrm{ab}}$ & $19.33 \pm 2.21 \mathrm{ab}$ & $21.27 \pm 2.59^{\mathrm{a}}$ & $11.63 \pm 1.91^{c}$ & $12.63 \pm 1.21^{\mathrm{c}}$ & $12.47 \pm 1.54^{\mathrm{c}}$ & $15.43 \pm 0.85 \mathrm{bc}$ \\
\hline & P3 & $17.50 \pm 4.16^{\mathrm{a}}$ & $17.60 \pm 1.80^{a}$ & $18.84 \pm 2.86^{a}$ & $10.93 \pm 1.31^{b}$ & $11.23 \pm 1.46^{b}$ & $10.30 \pm 0.75^{b}$ & $13.20 \pm 1.31^{b}$ \\
\hline
\end{tabular}




\section{International Journal of Agriculture, Environment and Bioresearch}

Vol. 4, No. 04; 2019

ISSN: $2456-8643$

\begin{tabular}{|c|c|c|c|c|c|c|c|c|}
\hline & P1 & $1.80 \pm 0.36^{\mathrm{ab}}$ & $1.83 \pm 0.45^{\mathrm{a}}$ & $1.97 \pm 0.45^{\mathrm{a}}$ & $0.83 \pm 0.25^{\mathrm{c}}$ & $1.13 \pm 0.21^{\mathrm{c}}$ & $1.30 \pm 0.26^{\mathrm{bc}}$ & $1.57 \pm 0.45^{\mathrm{abc}}$ \\
\cline { 2 - 7 } & P2 & $1.43 \pm 0.42^{\mathrm{a}}$ & $1.17 \pm 0.12^{\mathrm{ab}}$ & $1.60 \pm 0.56^{\mathrm{a}}$ & $0.50 \pm 0.61^{\mathrm{b}}$ & $0.80 \pm 0.30^{\mathrm{ab}}$ & $1.07 \pm 0.21^{\mathrm{ab}}$ & $1.27 \pm 0.45^{\mathrm{ab}}$ \\
\cline { 2 - 7 } & & & & & & \\
\hline \multirow{3}{*}{ RDW } & P3 & $0.77 \pm 0.42^{\mathrm{a}}$ & $0.87 \pm 0.15^{\mathrm{a}}$ & $1.37 \pm 0.49^{\mathrm{a}}$ & $0.83 \pm 0.55^{\mathrm{a}}$ & $0.67 \pm 0.38^{\mathrm{a}}$ & $0.73 \pm 0.21^{\mathrm{a}}$ & $1.10 \pm 0.35^{\mathrm{a}}$ \\
\hline
\end{tabular}

* Means \pm standard error within a column followed by the same letter are not significantly different according to Duncan's test at $\mathrm{P}<0.05$.

* T1: Control (-), T2: Control (+) (Tachigaren), T3: treated only with essential oil, T4: Plants inoculated only with FOL, T5: Plants inoculated and treated with fungicide, T6: Plants treated with essential oil before inoculation and T7: Plants inoculated and treated with essential oil after inoculation.

Table 3. Treatment effects on fruit number (FN) and average fruit weight (FW) of the tomato plants grown under different treatment.

\begin{tabular}{|c|c|c|c|c|c|c|c|}
\hline Treatment & T1 & T2 & T3 & T4 & T5 & T6 \\
\hline FN & $10.00 \pm 3.77^{\mathrm{a}}$ & $9.78 \pm 2.16^{\mathrm{a}}$ & $10.00 \pm 3.00^{\mathrm{a}}$ & $5.44 \pm 3.67^{\mathrm{a}}$ & $9.00 \pm 2.73^{\mathrm{a}}$ & $9.33^{\mathrm{a}} \pm 4.41^{\mathrm{a}}$ & $9.44 \pm 2.35^{\mathrm{a}}$ \\
\hline FW & $47.65 \pm 5.84^{\mathrm{a}}$ & $44.08 \pm 11.43^{\mathrm{a}}$ & $49.33 \pm 6.79^{\mathrm{a}}$ & $5.64 \pm 2.29^{\mathrm{d}}$ & $27.55 \pm 11.22^{\mathrm{b}}$ & $14.27 \pm 9.30^{\mathrm{c}}$ & $40.28 \pm 11.47^{\mathrm{a}}$ \\
\hline
\end{tabular}

* Means \pm standard error within a column followed by the same letter are not significantly different according to Duncan's test at $\mathrm{P}<0.05$.

* T1: Control (-), T2: Control (+) (Tachigaren), T3: treated only with essential oil, T4: Plants inoculated only with FOL, T5: Plants inoculated and treated with fungicide, T6: Plants treated with essential oil before inoculation and T7: Plants inoculated and treated with essential oil after inoculation.

\subsubsection{Fusarium wilt severity}

Wilt disease symptoms started to appear 3 weeks after inoculation as chlorose of leaves followed by a progressive wilting, stunting and finally death of plant. Vascular browning, leaf yellowing and wilting were remarkably reduced when plants were grown in presence of fungicide and fennel essential oil. Tomato plants inoculated but not treatment exhibited typical vascular browning, leaf yellowing and wilting, while treated plants appeared healthy with more subdued symptoms. Treatment of tomato plants with fungicide and fennel essential oil also allowed reducing root system damage compared to inoculated untreated plants (Figure 4).

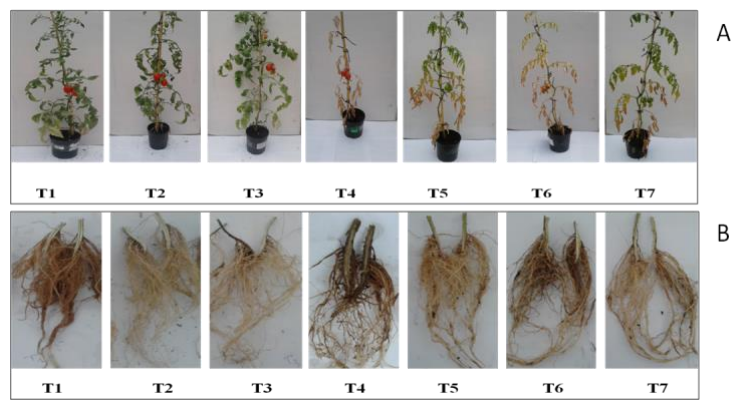


Figure 4: Fusarium wilt incidence in tomato plants (A) and roots (B).T1: Control (-), T2: Control (+) (Tachigaren), T3: treated only with essential oil, T4: Plants inoculated only with FOL, T5: Plants inoculated and treated with fungicide, T6: Plants treated with essential oil before inoculation and T7: Plants inoculated and treated with essential oil after inoculation.

Highlighting the phenomenon of systemic acquired resistance is essentially based on the measurement of the disease incidence reduction in treated plants compared with positive control. The evaluation of disease incidence inhibition was achieved 4 weeks after inoculation and the obtained results are shown in figure 5. This figure clearly demonstrated that disease incidence percentage was gradually increased with increasing infection period in non infected control as well as in essential oil or fungicide treated plants. All applied treatments of fennel essential oil either before or after inoculation and the fungicide protected tomato plants against Fusarium wilt. Most effective control of infection was found in plants treated by standard fungicide (54.08\%, $35.71 \%$ and $34.95 \%$ respectively after 28,42 and 56 days of infection). Treatment with fennel essential oil 14 days after inoculation seems to be more effective.

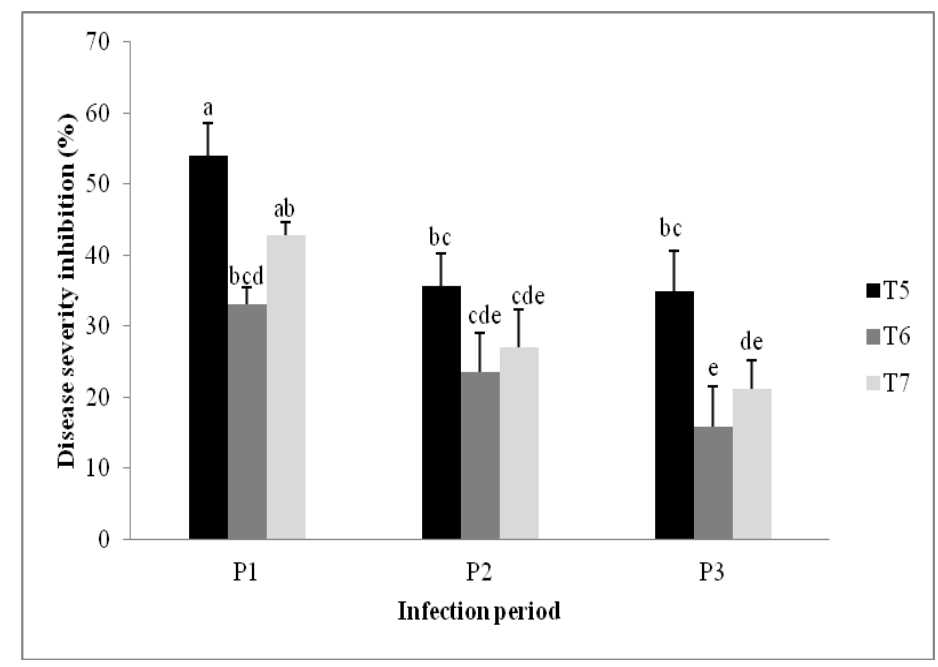

Figure 5: Fusarium wilt inhibition in tomato plants treated with standard fungicide (T5) and fennel essential oil (T6, T7) at 28, 42 and 56 days after treatment. Values are the means of three replicates. Different letters above columns indicate significant differences according to Duncan's test at $\mathrm{P} \leq 0.05$.

\subsubsection{Chlorophyll content}

Treatments significantly influenced chlorophylla content, chlorophyll $\mathrm{a} / \mathrm{b}$ ratio and carotenoids content (Table 4), in contrast with the statistical analysis showing no significant difference among treatments in chlorophyll $\mathrm{b}$ and $\mathrm{t}$ contents. 
Table 4. Effect of standard fungicide and fennel essential oil on photosynthetic pigments (mg/ fresh weight $(\mathrm{FW})$ ) of healthy and infected tomato plants with Fusarium oxysporum $\mathrm{f}$. sp. Lycopersici.

\begin{tabular}{|c|c|l|l|l|l|}
\hline Treatment & Chlorophyll a & $\begin{array}{c}\text { Chlorophyll } \\
\mathbf{b}\end{array}$ & $\begin{array}{l}\text { Chlorophyll } \\
\mathbf{a} / \mathbf{b}\end{array}$ & Chlorophyll t & Carotenoids \\
\hline T1 & $7.30 \pm 1.09^{\mathrm{ab}}$ & $\begin{array}{l}12.18 \pm 1.86 \\
\mathbf{a}\end{array}$ & $0.59 \pm 0.01^{\mathrm{b}}$ & $\begin{array}{l}19.48 \pm 2.94 \\
\mathrm{a}\end{array}$ & $0.39 \pm 0.06^{\mathrm{a}}$ \\
\hline T2 & $6.47 \pm 0.89^{\mathrm{ab}}$ & $\begin{array}{l}11.21 \pm 2.51 \\
\mathbf{a}\end{array}$ & $0.58 \pm 0.07^{\mathrm{b}}$ & $\begin{array}{l}17.66 \pm 3.35 \\
\mathrm{a}\end{array}$ & $0.34 \pm 0.02^{\mathrm{ab}}$ \\
\hline T3 & $6.59 \pm 0.38^{\mathrm{ab}}$ & $\begin{array}{l}12.20 \pm 0.87 \\
\mathrm{a}\end{array}$ & $0.54 \pm 0.01^{\mathrm{bc}}$ & $\begin{array}{l}18.78 \pm 1.14 \\
\mathrm{a}\end{array}$ & $0.36 \pm 0.05^{\mathrm{ab}}$ \\
\hline T4 & $5.78 \pm 0.18^{\mathrm{b}}$ & $\begin{array}{l}12.15 \pm 0.11 \\
\mathrm{a}\end{array}$ & $0.47 \pm 0.04^{\mathrm{c}}$ & $\begin{array}{l}17.93 \pm 0.09 \\
\mathrm{a}\end{array}$ & $0.09 \pm 0.02^{\mathrm{c}}$ \\
\hline T5 & $5.79 \pm 2.07^{\mathrm{b}}$ & $\begin{array}{l}11.41 \pm 3.23 \\
\mathrm{a}\end{array}$ & $0.49 \pm 0.02^{\mathrm{c}}$ & $\begin{array}{l}17.20 \pm 5.28 \\
\mathrm{a}\end{array}$ & $0.29 \pm 0.08^{\mathrm{ab}}$ \\
\hline T6 & $6.97 \pm 0.27^{\mathrm{ab}}$ & $\begin{array}{l}12.01 \pm 0.09 \\
\mathrm{a}\end{array}$ & $0.58 \pm 0.02^{\mathrm{b}}$ & $\begin{array}{l}18.97 \pm 0.27 \\
\mathrm{a}\end{array}$ & $0.29 \pm 0.01^{\mathrm{b}}$ \\
\hline T7 & $8.17 \pm 0.28^{\mathrm{a}}$ & $\begin{array}{l}11.72 \pm 0.05 \\
\mathrm{a}\end{array}$ & $0.69 \pm 0.07^{\mathrm{a}}$ & $\begin{array}{l}19.87 \pm 0.33 \\
\mathrm{a}\end{array}$ & $0.35 \pm 0.06^{\mathrm{ab}}$ \\
\hline
\end{tabular}

* Means \pm standard error within a column followed by the same letter are not significantly different according to Duncan's test at $\mathrm{P}<0.05$.

*T1: Control (-), T2: Control (+) (Tachigaren), T3: treated only with essential oil, T4: Plants inoculated only with FOL, T5: Plants inoculated and treated with fungicide, T6: Plants treated with essential oil before inoculation and T7: Plants inoculated and treated with essential oil after inoculation.

Comparison of chlorophyll values between inoculated (T4) and healthy control (T1) indicated a negative effect of FOL on photosynthesis process. Indeed, Data in Table 4 revealed that infection of tomato plants with the pathogen resulted in a decrease in chlorophylla in the leaves of inoculated plants $(5.79 \mathrm{mg} / \mathrm{g} \mathrm{FW})$ as compared with the healthy plants $(7.3 \mathrm{mg} / \mathrm{g} \mathrm{FW})$. The same pattern of a lower chlorphyll $\mathrm{a} / \mathrm{b}$ ratio in infected plants $(0.47)$ compared with the healthy ones (0.63) was also found. Essential oil application overcomes the negative effect of Fusarium oxysporum f. sp. lycopersici. In fact, total photosynthetic pigments and carotenoids contents of leaves also increased considerably as a result of soil treatment with fennel essential oil and the maximum values of total pigment content were observed in plants grown in pots treated with fennel essential oil after inoculation (Chlorophyll a $=8.17 \mathrm{mg} / \mathrm{g} \mathrm{FW}$, Chlorophyll $\mathrm{t}=19.88 \mathrm{mg} / \mathrm{g}$ $\mathrm{FW}$ and carotenoids $=0.35 \mathrm{mg} / \mathrm{g} \mathrm{FW}$ ).

\subsubsection{Relative water content}


Fennel essential oil and fungicide applications showed a significant enhancement in RWC when compared with Fusarium-infected and uninfected control. The RWC was estimated to be more in plants undergoing curative treatment with an increase of $5.77 \%$ compared to the healthy control in the absence of infection and an increase of $35.32 \%$ compared to the infected control (Figure 6).

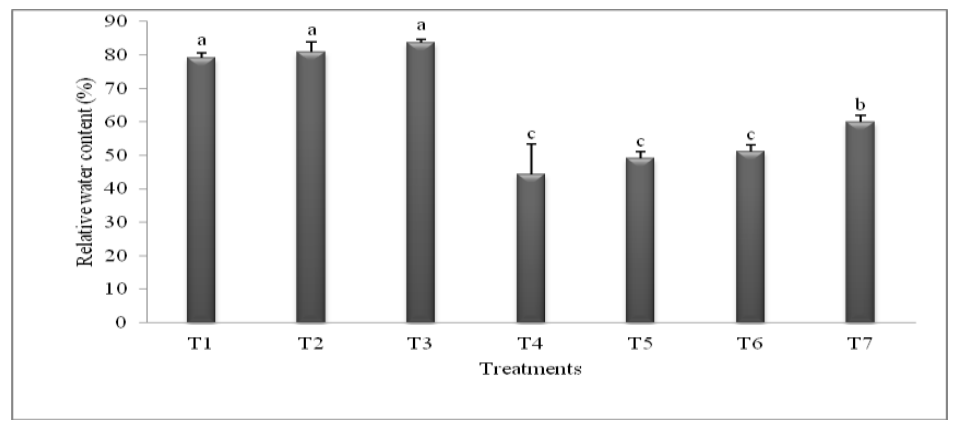

Figure 6: Effect of fungicide and fennel essential oil on relative water content (\%) of healthy and infected tomato plants with Fusarium oxysporum f. sp. lycopersici. T1: Control (-), T2: Control (+) (Tachigaren), T3: treated only with essential oil, T4: Plants inoculated only with FOL, T5: Plants inoculated and treated with fungicide, T6: Plants treated with essential oil before inoculation and T7: Plants inoculated and treated with essential oil after inoculation. Different letters above columns indicate significant differences according to Duncan's test at $\mathrm{P} \leq 0.05$.

\subsection{Stepwise analysis}

A multiple linear regression (stepwise procedure) was performed to explain disease incidence variations as the dependent variable at three infection periods. All morphological and physiological traits measured in tomato plants under different treatments and during three infection period were used as independent variables (Table 5).

Table 5. Multiple linear regressions (stepwise) explaining disease incidence (DI) variation as a dependent variable, and all the growth traits, leaf chlorophyll content, carotenoids content, relative water content, under seven treatments and during three infection periods, as independent variables.

\begin{tabular}{|c|c|c|c|c|}
\hline Dependent variable & Environment & Variable chosen & $\mathbf{R}^{\mathbf{2}}$ & Significance \\
\hline DI & Date 1 & $\mathrm{Ca}$ & 0.603 & $* *$ \\
& & $\mathrm{Ca}-\mathrm{Chlt}$ & 0.797 & $* * *$ \\
\hline DI & Date 2 & $\mathrm{Ca}$ & 0.607 & $* *$ \\
\hline DI & Date 3 & $\mathrm{Ca}-\mathrm{H}$ & 0.792 & $* *$ \\
& & & 0.556 & \\
\hline
\end{tabular}

Levels of significance: $* * * \mathrm{P}<0.001 ; * \mathrm{P}<0.05$; ns: not significant. 
At 28 days after inoculation, carotenoids content was the first variable selected by the model (60\% of the variability) in disease incidence, followed by total chlorophyll content.

Stepwise analyses were also performed during two longer infection period (42 and 56 days after inoculation). At 42 days after inoculation, carotenoids content and plant height were chosen to explain, collectively, $79 \%$ of the disease incidence variation. At 56 days after inoculation, carotenoids content was chosen by the model as the only determinant component for the disease incidence variation $(55 \%)$.

Other variables related to agro-morphological traits (except for the plants length), chlorophyll a, chlorophyll $\mathrm{b}$, and relative water contents were not chosen by the model in none of the cases. In fact, they showed a week and non-significant correlation with disease incidence (data not shown).

\subsection{Principal component analysis (PCA)}

PCA analysis explained, by two factors, $65.82 \%$ of the cumulative variance. The first factor explained $40.97 \%$ and the second factor explains $24.85 \%$ (Figure 7 ). The analysis showed 3 main groups. The first group was formed by root fresh weight, root dry weight, aerial and root biomass. The second one included carotenoids, aerial dry weight and chlorophyll a. While the rest of the parameters are in the third group formed by morphological traits, relative water content, chlorophyll $b$ and chlorophyll $t$. These three groups were diametrically opposed to the disease incidence in relationship to the principal component axis (PCA2).

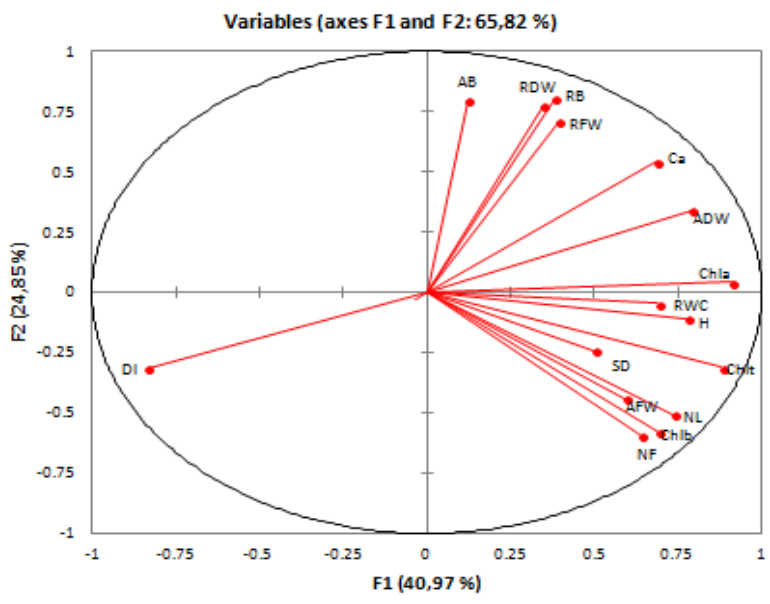

Figure 7: Principal Component Analysis (PCA 1 and PCA 2) of agronomical and physiological traits measured in tomato plants following the seven treatments.

\section{DISCUSSION}

Recently, there has been considerable emphasis on essential oils and spices extracts and their constituents to reduce the hazards of chemicals intensive use to control plants diseases. In the present investigation, antifungal activity of essential oil fennel seeds against Fusarium oxysporum f. sp. lycopersici was studied in tomato plants. Trans-anethole, fenchone, estragole and limonene were identified as the highest-level main constituents. Most results of works 
conducted on fennel, in agreement with those reported by our study, showed the abundance of trans-anethol in essential oils seeds $(60.42 \%-87.85 \%)$ [18] - [19] - [20]. Several essential oil components of this plant have important applications, namely, trans-anethole the dominant component, which was found in other plant essential oils, has been reported to possess insecticidal, larvicidal, and antimicrobial activities [21]. According to Huang et al. [22], transanethole had a wide inhibitory spectrum of capacity against plant pathogenic fungi, namely Alternaria solani, Bipolaris maydis, Botryodiplodia theobromae, Fusarium graminearum, Fusarium oxysporum f. sp. cucumerinum, Fusarium oxysporum f. sp. lycopersici, Fusarium oxysporum f. sp. vasinfectum, Magnaporthe oryzae, Pythium aphanidermatum, Rhizoctonia cerealis, and Rhizoctonia solani. This makes fennel essential oil an appropriate candidate as a bio-fungicide and therefore considered as an alternative to the chemical fungicides against phytopathogenic fungi. Trans anethole that is the major component in this essential oil, may be responsible for this fungitoxic sensitiveness. Results of the antifungal effects of fennel essential oil, in vitro, showed strong and varying levels of inhibitory effects on the experimental fungi growth depending on the applied concentration. Many studies have been conducting to investigate the antifungal activity of fennel. Indeed, seeds essential oil had inhibitory activity against Alternaria, Fusarium solani, Penicillium, Phytophthora infestans, Rhizopus solani, Fusarium oxysporum, Paenihacillus larvae, and Rhizopus solani [9] - [13]. This makes fennel essential oil an appropriate candidate as a bio-fungicide and therefore considered as an alternative to the chemical fungicides against phytopathogenic fungi. Trans anethole that is the major component in this essential oil, may be responsible for this fungitoxic sensitiveness.

Measurements of morphological traits related to vegetative growth, flowering and yield revealed that tomato plants infected with the pathogen showed a reduction in most growth parameters. Inhibition plant growth may be due to the toxins produced by the pathogen, which affected stomata function and potassium uptake leading to uncontrolled transpiration and excessive loss of water and ultimately result in wilted plants [23]. These alterations in growth could also be due to the energy demands by the host-parasite interaction and low dry matter accumulation caused by inefficient $\mathrm{CO}_{2}$ assimilation [24]. Moreover, Hassanein et al. [25] explained the decrease of inoculated plant growth by the accumulation and action of phenolic compounds synthesized by lignin degradation of the cell wall, mainly by depolymerization, which is a result of fungal elicitors. Pshibytko et al. [26] explained this effect of Fusarium on reduction growth of tomato plants by the nutrients deficit and poisoning by fungal toxins, such as fusaric acid, lycomarasmin, vasinfuscarin, and some enzymes (polygalacturonase and pectin methylesterase). According to Berger et al. [27] pathogen attacks usually reduced the photosynthesis activity and consequently declines plants yield. Increase of plant growth parameters can also be due to release of many antibiotic substances which are inimical to pathogenic fungi resulting in death or lysis of pathogens or by indirect toxic effect of volatile substances. Similar results were obtained by Hassanein et al. [25] and El-Khallal [28] who found that treatment of infected plants with plant extracts such as basilic, neem and chinaberry extracts was highly effective on growth promotion and protection of tomato against Fusarium wilt. Several plants contain common growth-promoting substances, such as essential oils. This beneficial effect of biostimulants on plant growth has been explained by Rafaiee et al. [29], as a consequence of their influence on plant metabolism. Indeed, they improve the natural hormones synthesis and activities; they also facilitate the consumption of nutrients from the substrate, and stimulate root growth. Disease 
incidence management is based on integrated control by crop rotation, cultural techniques, disease-resistant cultivars and biological control [3]. Likewise, several studies demonstrated that plant extracts can effectively protect plants against pathogens by inducing systemic resistance [30].This effect was explained by Farag Hanaa et al. [31], who revealed that fusarium wilt disease resistance in tomato by plant extracts may be due to the presence of biological active compounds which have either direct antimicrobial activities or induce host plants defense response resulting in a reduction of disease development. Foliar symptoms in the case of pathogens attack were linked to the photosynthetic apparatus alteration and stomatal closure. It has been reported that toxins produced by Fusarium oxysporum inhibits chlorophyll biosynthesis leading to Fusarium wilt disease [32]. Fungal root pathogen can affect various physiological processes, as gas exchange or water absorption, and thus resulting in decrease of the photosynthetic activity. Noguès et al. [33] estimated that the effect of Fusarium infection on leaf photosynthesis is connected to water stress. During the first stage of the disease, Fusarium wilt inhibits the light-saturated rate of $\mathrm{CO}_{2}$ assimilation, this was accompanied by reduction in the capacity for regeneration of ribulose-1,5-bisphophate and the maximum carboxylation velocity, in the absence of any significant photodamage to photosystem II, these leaves had a most important rate of non cyclic electron transport than that intended to preserve $\mathrm{CO}_{2}$ assimilation. These authors also suggested that Fusarium oxysporum increased stomatal restriction of the $\mathrm{CO}_{2}$ supply and as the disease progressed, the maximum quantum efficiency of photosystem II photochemistry diminish in the leaves. Other authors also mentioned the negative effect of fungal infection on photosynthetic parameters and explained the decrease in photosynthetic pigments of tomato plants infected with Fusarium oxysporum by the fungal effect on the liberation of transported toxins, which directs the release of reactive oxygen species (ROS) [28] or by the increase of lipid peroxidation wich mediate cell damage in tomato plant tissues [34]. Previous studies suggested that carotenoids are involved in the antioxidation process of the cell under several environmental stresses due to its redox properties [35]. Carotenoids act also as hydrogen donors or reducing agents for scavenging oxygen, detoxifying free radicals, or decomposing peroxides [36]. In our study, treated plants showed a significant improve carotenoid contents compared to infected plants. Expression of such enhanced carotenoid contents is indicative of antioxidant capacity which would be imparting major role in maintaining the cellular redox state and this by removing excess hydrogen peroxide at cellular level. This effect of plant extract could be attributed to its role in activation of regulating enzymes of photosynthetic carbon reduction and which protect chloroplast from oxidative deteriorate [37]. This antioxidant effectiveness of fennel seeds essential oil in the regulation of photosynthesis could be due to major compounds such as anethole, an oxygenated monoterpene known for its antioxidant capacity [38]. Significant differences were observed between infected and non infected plants for the relative water content. Similar observations have been recorded on physiological parameters related to water supply in case of Fusarium oxysporum infection. Pshibytko et al. [26] and Nogués et al. [33] showed that the relative water content (RWC) in plant leaves considerably decreased during fusarium wilt development. These authors concluded that Fusarium infection effect in tomato plants was mimicked by water stress. According to Pshibytko et al. [26], fusarium wilt was developed when microspores of pathogen penetrated into the xylem and thereafter propagated into the phloem through parenchyma rays, where mycelium of the pathogen grew extremely. Consequently, the vascular bundles of the xylem and, 
especially, the phloem, through which assimilates are flowing, were clogged with mycelium. Thus, flows of the xylem and phloem were suppressed, causing the establishment of the shortage of nutrients and water deficit in the plant. On the other hand, Nogués et al. [33] and Aguirreolea et al. [39] are in agreement with the hypothesis that suggests the physical blockage of fusarium on leaf photosynthesis. These authors proved that vascular wilt pathogens raise the resistance to water movement as a consequence of lessen diameter of the conductive elements. This reduction can be influenced by several factors such as the physical presence of the pathogen, their metabolites, extracellular enzymes or by provoking the gummy substances and tyloses formation in the conductive tissues. At 28 and 42 days after inoculation, stepwise analysis showed that carotenoids followed by total chlorophyll contents and plant height are the parameters that discriminate best between treatments. However, at 56 days after inoculation, carotenoids content was the most reliable parameters to distinguish the effectiveness of different treatments in reducing disease incidence. The reduced disease intensity indicates that some metabolites must be associated with induction of resistance against the pathogen. Our results reinforce the importance of carotenoids and chlorophyll accumulations at the infection site to restrict the pathogens development, since these compounds are toxic to pathogens.

\section{CONCLUSION}

In this study, different concentrations of the fennel essential oil were found to inhibit the in vitro growth of FOL in a dose-dependent manner. Fennel essential oil was also evaluated in its capacity to protect tomato plants under greenhouse. All agro-physiological and physiological traits of tomato plants are strongly influenced under Fusarium oxysporum infection. Plant growth has been regulated and even improved in healthy plants. Disease incidence was reduced by fennel essential oil application. This can result from the combination of a direct antifungal activity of essential oils, shown in the in vitro assay, and the induction of defense responses which have already been proven by the regulation of physiological parameters relating to chlorophyll pigments and the relative water content. Among the tested treatments, fennel oil seems to be more effective when applied after inoculation. Thus, induction of the plant's defense mechanism by essential oils applications may be a new strategy in plant disease management. The development of these natural fungicides would help to decrease the negative impact of synthetic agents, such as resistance, residues, and environmental pollution.

\section{REFERENCES}

[1] H.A. Salim, I.S. Salman, Jasim, B.N, "IPM Approach for the management of wilt disease caused by Fusarium oxysporum f. sp. lycopersici on tomato (Lycopersicon esculentum)," Journal of Experimental Biology and Agricultural Sciences, 4, pp. 742747, 2016.

[2] S. Soro, K. Abo, D. Kone, K. Coffi, J.Y. Kouadio, S. Ake, “Comparaison de l'efficacité antifongique de l'huile essentielle d'Ocimum gratissimum L. et du fongicide de synthèse Mancozebe contre le mycopathogène tellurique Fusarium oxysporum f. sp. Radicislycopersici en culture de tomate (Lycopersicon esculentum Mill.) sous abri en côte d'ivoire," Agronomie Africaine, 23, pp. 43-52, 2011. 
[3] J. Amini and D.F. Sidovich, "The effects of fungicides on Fusarium oxysporum f. sp. Lycopersici associated with Fusarium wilt of tomato," Journal of Plant Protection Research, 50, pp. 172-178, 2010.

[4] S. Siripornvisal, "Biocontrol efficacy of Bacillus subtilis BCB3-19 against tomato gray mold," The KMITL Science and Technology Journal, 10, pp. 37-44, 2010.

[5] A. Kumar and S.K. Buswas, "Biochemical evidences of induced resistance in tomato plant against Fusarium with through inorganic chemicals," Journal of Mycopathological Research, 2, pp. 213-219, 2010.

[6] S.N. Dixit, H. Chandra, R. Tiwari, D. Dixit, "Development of a botanical fungicide against blue mould of mandarins, "Journal of stored products research, 31, pp. 165-172, 1995.

[7] C.F. Bagamboula, M. Uyttendaele, J. Debevere, "Inhibitory effect of thyme and basil essential oils, carvacrol, thymol, estragol, linalool and p-cimene towards Shigella sonnei and S. flexneri," Food Microbiology, 21, pp. 33-42, 2004.

[8] K.R.F. Schwan-Estrada and J.R. Stangarlin, "Extratos e óleos essenciais de plantas medicinais na indução de resistência," In: L.S. Cavalcanti, R.M. Di Piero, P. Cia, S.F. Paschoati, M.L.V. Resende, R.S. Romeiro, "Indução de resistência em plantas a patógenos e insetos, " Piracicaba: Fealq, pp. 125-132, 2005.

[9] M.M. Özcan, J.C. Chalchat, D. Arslan, A. Ates, A. Unver, "Comparative essential oil composition and antifungal effect of bitter fennel (Foeniculum vulgare ssp. Piperitum) fruit oil obtained during different vegetation, ” Journal Medicinal Food, 9, pp. 552-561, 2006.

[10] W. Kooti, M. Moradi, S. Ali-Akbari, N. Sharafi-Ahvazi, M. Asadi-Samani, D. Ashtary-Larky, "Therapeutic and pharmacological potential of Foeniculum vulgare Mill: A review," Journal of Herbmed Pharmacology, 4 (1), pp. 1-9, 2015.

[11] K.J. Al-Hadid, "Quantitative analysis of antimicrobial activity of Foeniculum vulgare: A review," Plant Omics Journal, 10, pp. 28-36, 2017.

[12] I. Bettaieb, S. Bourgou, J. Sriti, K. Msaada, F. Limam, B. Marzouk, "Essential oils and fatty acids composition of Tunisian and Indian cumin (Cuminum cyminum L.) Seeds: a comparative study, " Journal of the Science of Food and Agriculture, 91, pp. 2100-2107, 2011.

[13] E.M. Soylu, S. Soylu, S. Kurt, "Antimicrobial activities of the essential oils of various plants against tomato late blight disease agent Phytophthora infestans," Mycopathologia, 161, pp 119-128, 2006.

[14] E.S. Carmo, E.O. Lima, E.L. Souza, "The potential of Origanum vulgare L. (Lamiaceae) essential oil in inhibiting the growth of some food-related Aspergillus species," The Brazilian Journal of Microbiology 39, pp. 362-367, 2008.

[15] W. Song, L. Zhou, C. Yang, X. Cao, L. Zhang, X. Liu, "Tomato Fusarium wilt and its chemical control strategies in a hydroponic system, " Crop Protection, 23, pp. 243-247, 2004.

[16] H.K. Lichtenthaler and A.R. Wellburn, "Determination of Total Carotenoids and Chlorophylls A and B of Leaf in Different Solvents," Biochemical Society Transactions, 11, pp. 591-592, 1983. 
[17] J. M. Diiniway, "Pathogen-induced changes in host-water relations," Phytopathology, 63, pp. 458-466, 1973.

[18] M.B. Stefanini, L.C. Ming, M.O.M. Marques, R. Facanali, M.A.A. Meireles, L.S. Moura, J.A. Marchese, L.A. Sousa, "Essential oil constituents of different organs of fennel (Foeniculum vulgare var. vulgare), " The Revista Brasileira de Plantas Medicinais. 8, pp. 193- 198, 2006.

[19] I. Telci, I. Demirtas, A. Sahin, "Variation in plant properties and essential oil composition of sweet fennel (Foeniculum vulgare Mill.) Fruit during stages of maturity," Industrial Crops and Products, 30, pp. 126-130, 2009.

[20] A.C. Aprotosoaie, A.D. Spac, M. Hancianu, A. Miron, V.F. Tanasescu, V. Dorneanu, U. Stanescu, "The chemical profile of essential oils obtained from fennel fruits (Foeniculum vulgare Mill.)," Farmacia, 58, pp. 46-54, 2010.

[21] M. Tognolini, V. Ballabeni, S. Bertoni, R. Bruni, M. Impicciatore, E. Barocelli, "Protective effect of Foeniculum vulgare essential oil and anethole in an experimental model of thrombosis, " Pharmacological Research. 56, pp. 254-260, 2007.

[22] Y. Huang, J. Zhao, L. Zhou, J. Wang, Y. Gong, X. Chen, Z. Guo, Q. Wang, W. Jiang, "Antifungal Activity of the Essential Oil of Illicium verum Fruit and Its Main Component trans-Anethole," Molecules. 15, pp.7558-7569, 2010.

[23] P. Aducci, A. Ballio, M. Marra, "Phytotoxins as molecular signals," in Molecular and Cell Biology Updates. P. Aducci (eds.), Birkhauser Verlag, Basel, pp. 83-105, 1997.

[24] K.J. Michael, "Rate of photosynthesis in coconut palm affected by root wilt disease," Placrosym. 1, pp. 372, 1978.

[25] N.M. Hassanein, M.A. Abou Zeid, K.A. Youssef, D.A. Mahmoud, "Efficacy of leaf extracts of Neem (Azadirachta indica) and chinaberry (Melia azedrach) against early blight and wilt diseases of tomato," Australian Journal of Basic and Applied Sciences, 2, pp. 763-772, 2008.

[26] N.L. Pshibytko, L.A. Zenevich, L.F. Kabashnikova, "Changes in the Photosynthetic Apparatus during Fusarium Wilt of Tomato," Fiziologiya Rastenii, 53, pp. 31-37, 2005.

[27] S. Berger, A.K. Sinha, T. Roitsch, "Plant physiology meets phytopathology: plant primary metabolism and plant-pathogen interactions," Journal of Experimental Botany, 58, pp. 4019-4026, 2007.

[28] S.M. El- Khallal, "Induction and modulation of resistance in tomato plants against Fusarium wilt disease by bioagent fungi (Arbuscular Mycorrhiza) and/or hormonal elicitors (jasmonic acid \& salicylic acid): changes in growth, some metabolic activities and endogenous hormones related to defence mechanism," Australian Journal of Basic and Applied Sciences, 1, pp. 691-705, 2007.

[29] H. Rafaiee, B.H. Nghdi, A. Mehrafarin, A. Qaderi, N. Zarinpanjeh, A. Sekara, E. Zand, "Application of Plant Biostimulants as New Approach to Improve the Biological Responses of Medicinal Plants-A critical Review," Journal of Medicinal Plants 15, pp. 34, 2016.

[30] E. Llorens, P. García-Agustín, L. Lapeña, "Advances in induced resistance by natural compounds: towards new options for woody crop protection," Scientia Agricola, 74, pp. 90-100, 2017. 
International Journal of Agriculture, Environment and Bioresearch

Vol. 4, No. 04; 2019

ISSN: $2456-8643$

[31] R.M. Farag Hanaa, Z.A. Abdou, D.A. Salama, , M.A.R. Ibrahim, H.A.M. Sror, "Effect of neem and willow aqueous extracts on fusarium wilt disease in tomato seedlings: Induction of antioxidant defensive enzymes," Annals of Agricultural Science, 56, pp. 1-7, 2011.

[32] DS. Achor, S. Nemec, R.A. Baker, "Effects of Fusarium solani naphthazarin toxins on the cytology and ultrastructure of rough lemon seedlings," Mycopathologia, 123, pp.117-126, 1993.

[33] S. Nogués, L. Cotxarrera, A. Leonor, I.T. Maria, "Limitations to photosynthesis in tomato leaves induced by Fusarium wilt," New Phytologist, 154, pp. 461-470, 2002.

[34] G. Haberer and J. Kierber, "Cytokinins. New insights into a classic phytohormone," Plant Physiology 128, pp. 345-362, 2002.

[35] A. Fini, C. Brunetti, M. Di Ferdinando, F. Ferrini, M. Tattini, "Stress-induced flavonoid biosynthesis and the antioxidant machinery of plants, " Plant Signaling \& Behavior, 6 (5), pp. 709-711, 2011.

[36] C.H. Beckman, "Phenolic-storing cells: keys to programmed celldeath and periderm formation in wilt disease resistance and in general defence responses in plants," Physiological and Molecular Plant Pathology, 57, pp. 101-110, 2000.

[37] S. A. Akladious, G. S. Isaac, M. A. Abu-Tahon, "Induction and resistance against Fusarium wilt disease of tomato by using sweet basil (Ocimum basilicum L) extract, " Canadian Journal of Plant Science, 95, pp. 689-701, 2014.

[38] B. Muckensturm, D. Foechterlen, J.P. Reduron, P. Danton, M. Hildenbrand, "Phytochemical and chemotaxonomic studies of Foeniculum vulgare," Biochemical Systematics and Ecology, 25, pp. 353-358, 1997.

J. Aguirreolea, J. Irigoyen, M. Sanchez-Diaz, J. Salaverri, "Physiological alterations in pepper during wilt induced by Phytophthora capsici and soil water deficit, " Plant Pathology, 44, pp. 587-596, 1995 